\title{
A novel mouse model of penetrating brain injury
}

\author{
Ibolja Cernak ${ }^{1}$, Ian D. Wing ${ }^{2}$, Johan Davidsson ${ }^{3}$ and Stefan Plantman ${ }^{4}$ * \\ 'Military and Veterans' Clinical Rehabilitation Research, University of Alberta, Edmonton, AB, Canada \\ 2 Johns Hopkins University Applied Physics Laboratory, Laurel, MD, USA \\ ${ }^{3}$ Division of Vehicle Safety, Chalmers University of Technology, Göteborg, Sweden \\ ${ }^{4}$ Department of Neuroscience, Karolinska Institutet, Stockholm, Sweden
}

\section{Edited by:}

Mattias K. Sköld, Uppsala University, Sweden

Reviewed by:

Fredrik Clausen, Uppsala University, Sweden

Bridgette D. Semple, University of California San Francisco, USA

*Correspondence:

Stefan Plantman, Department of Neuroscience, Karolinska Institutet, Retzius väg 8, Stockholm S-171 77, Sweden

e-mail: stefan.plantman@ki.se
Penetrating traumatic brain injury (pTBI) has been difficult to model in small laboratory animals, such as rats or mice. Previously, we have established a non-fatal, rat model for pTBI using a modified air-rifle that accelerates a pellet, which hits a small probe that then penetrates the experimental animal's brain. Knockout and transgenic strains of mice offer attractive tools to study biological reactions induced by TBI. Hence, in the present study, we adapted and modified our model to be used with mice. The technical characterization of the impact device included depth and speed of impact, as well as dimensions of the temporary cavity formed in a brain surrogate material after impact. Biologically, we have focused on three distinct levels of severity (mild, moderate, and severe), and characterized the acute phase response to injury in terms of tissue destruction, neural degeneration, and gliosis. Functional outcome was assessed by measuring bodyweight and motor performance on rotarod. The results showed that this model is capable of reproducing major morphological and neurological changes of pTBl; as such, we recommend its utilization in research studies aiming to unravel the biological events underlying injury and regeneration after pTBI.

Keywords: traumatic brain injury, models of injury, penetrating ballistic-like brain injury, animal studies, gliosis, neurodegeneration, histology

\section{INTRODUCTION}

Penetrating traumatic brain injury (pTBI) occurs when an object impacts the head with sufficient energy to penetrate the skin, skull, and meninges and inflict injury directly to the brain tissue. Historical case studies of pTBI provided the best known information about human neurological functions. For example, the descriptions of injuries suffered by Phineas Gage (1), the soldier known in the medical literature under the pseudonym Zasetsky (2), and the patient known as N.A. (3) have greatly contributed to our understanding of the neurological mechanisms underlying normal or pathological sensation or cognitive processing. In general, pTBI is a severe type of injury, particularly prevalent in warzones $(4,5)$ and in areas with high incidence of gun-related violence (6). In contrast to closed head injury, pTBI involves direct laceration of brain tissue, often complicated by hemorrhage, edema, inflammation, higher risk of coagulopathy (7), and post-traumatic seizures (8). The presence of foreign objects such as bone- or missile-fragments might promote post-traumatic infection and worsen the outcome after pTBI $(9,10)$. Due to the complexity of severity of pTBI, special guidelines have been developed for its management (11).

To date, the number of animal models reproducing penetrating head injury is very limited. Cat (12), dog (13), monkey (14), and sheep (15) have all been used for this purpose, but none of these models are currently in routine use. Although anatomical and physiological properties of larger animal models might be more comparable to humans, rodents have the advantage of being easier to handle and due to their relatively small cost permit repetitive measurements of morphological, biochemical, and cellular parameters (16). Moreover, standardized and reproducible ways to measure outcome in terms of behavior are mainly available for rodents (17).

At current, there are only two rodent pTBI models: (1) the penetrating ballistic-like brain injury (PBBI) model in rats developed by Williams et al. (18), which simulates the large temporary cavity caused by energy dissipation from a penetrating bullet-round using an inflatable penetrating probe (18); and (2) our recently developed pTBI model (19) using a pellet accelerated by a modified air-rifle and hitting a probe, which then penetrates the brain of an anesthetized rat. The induced injury causes neuronal and axonal degeneration, blood-brain barrier (BBB)-defects, reactive gliosis, and functional impairment (19), and significantly differs from blast- and rotation-induced injuries in terms of induction of gene expression in the injured brain (20). Both above-mentioned rodent pTBI models have been designed for rats; however, bearing in mind some obvious advantages of using mice as experimental animals, such as gene-manipulation and smaller housing requirements (21), we redesigned and adapted our rat model for use with mice. This paper describes the initial technical testing and biological characterization of this new model.

\section{MATERIALS AND METHODS}

\section{DESIGN AND ADAPTATION OF THE pTBI DEVICE}

The rat version of the pTBI rig has been described previously (19). Briefly, a lead pellet (Accupell, Crossman, Bloomfield, NY, USA) is accelerated from a modified air-rifle (CNC-Process AB, Hova, Sweden) (Figure 1A) connected to a tank filled with compressed air. 


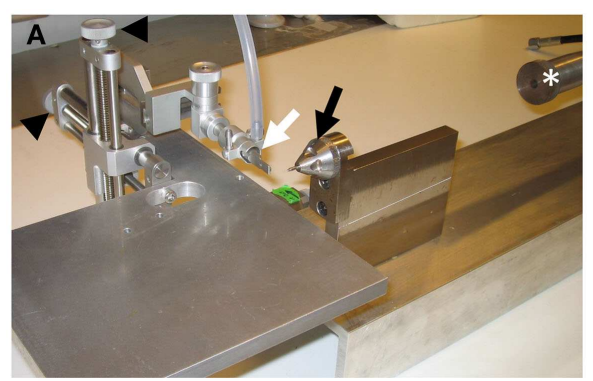

FIGURE 1 |The penetration device. (A) Photo of the penetration rig showing the mouthpiece (white arrow), probe holder (black arrow), stereotactic manipulators (black arrowheads), and air-rifle barrel (white asterisk). (B,C) Close-up of the probe holder and probe before (B) and
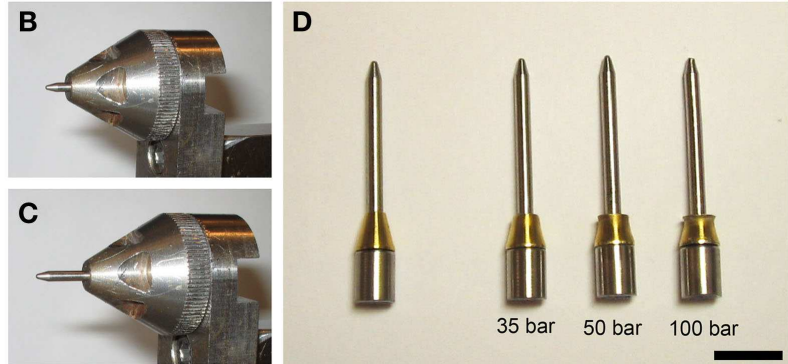

after (C) impact of pellet. Note the probe displacement (penetration) after impact (C). (D) Photo of probes after impact at loading-pressures of 35-, 50-, and 100-bar. Note deformation of the brass ferrule (scale bar $=10 \mathrm{~mm}$ ).
This pellet then hits a probe sitting in a holder (Figures 1B,C), and a brass ferrule (Swagelok, Solon, OH, USA) fitted around the probe controls the depth of penetration. The injury severity is varied by adjusting the air-rifle pressure. Given the smaller size of the mouse brain, which is approximately $6 \mathrm{~mm}$ from the top of the cortex to the median eminence in the coronal plane at bregma $-2.5 \mathrm{~mm}$ (22) as compared to approximately $10 \mathrm{~mm}$ for rats (23), we manufactured probes [diameter: $2 \mathrm{~mm}$ and weight $1.48 \mathrm{~g}$ (Figure 1D)] that reach a penetration depth of $3.55 \mathrm{~mm}$ before the ferrule, acting as a stopper, is engaged. Experience from the rat model showed that a probe with a pointed tip causes less tissue destruction than a probe with a blunt tip. Consequently, our mouse probes were made with a pointed tip. The previous experimental setup for rats with these two alterations induced injuries in mice similar to those seen in rats at 50-bar ( $5 \mathrm{MPa}$ ) loading-pressure (data not shown). In this study, we used the same injury severity criteria, determined by histology, as in our previous characterization (19). We chose the injury severity induced by 50-bar loading-pressure as the moderate injury level. A loading-pressure of 35-bar was considered a mild injury and the 100-bar loading-pressure was chosen as the upper limit inducing severe pTBI.

\section{PENETRATION DEPTH AND PROBE VELOCITY}

The depth of penetration was measured with a slide caliper, before and after the pellet impact. To capture the probe velocity at the impact (i.e., when the probe was impacted by the pellet but did not penetrate the brain), we used a Phantom V10 video camera (Vision Research, Wayne, NJ, USA) at 30,000 frames per second. Video images were analyzed frame-by-frame, and the velocity of the probe was determined.

\section{GEL INDENTATION MEASUREMENTS}

Ballistics gel (Gelatin innovations, Schiller Park, IL, USA) was prepared according to the manufacturers' instructions. ${ }^{1}$ Different concentrations have been tested in our lab to achieve the gel's best biological fidelity with the brain tissue, which have been reproduced by a 7\% gel. The gel was cast in a transparent box, and video recordings were made using similar settings as for probe velocity

${ }^{1}$ http://www.gelatininnovations.com/pages/ballistic_fast_ins.html measurements described in the previous section. Still images of maximum cavitation were used to trace the cavity profile, and the volume was determined using Cavalieri's volume estimation: $V=\Sigma t\left(\pi r^{2}\right)$, where $V$ is the total volume of the cavity, achieved by adding the individual volumes of the disks [thickness $(t)$ used were $0.5 \mathrm{~mm}$ and radius $(r)$ from video image analysis]. Videos of gel indentation can be found in the Supplementary Material.

\section{ANIMALS AND INJURY INDUCTION}

All protocols involving the use of animals were approved by the Johns Hopkins University Animal Use Committee. Male, young adult C57/Bl6 mice weighing between 25 and $28 \mathrm{~g}$ were used throughout the study. Mice were kept on a $12 \mathrm{~h}$ light/dark cycle, and provided with food and water ad libitum. For surgery, mice were initially anesthetized with $4 \%$ and then with $1-1.5 \%$ isoflurane for maintenance. The anesthetic was evaporated in a gas mixture containing $30 \%$ oxygen $/ 70 \%$ nitrous oxide and applied through a nose-mask. A midline incision was made through the skin and periosteum, and a burr-hole of $2.7 \mathrm{~mm}$ in diameter was drilled with its center $1.5 \mathrm{~mm}$ lateral, and $1.5 \mathrm{~mm}$ posterior to bregma. The animal was thereafter placed in a stereotactic frame (David Kopf Instruments, Tujunga, CA, USA) and positioned so that the impactor probe was positioned directly above the dura exposed by the burr-hole. Penetration was performed, and the mice were removed from the frame; the scalp was sutured and mice were given a subcutaneous injection of a mixture containing buprenorphine $(0.05 \mathrm{mg} / \mathrm{kg})$ and carprofen $(5 \mathrm{mg} / \mathrm{kg})$ in $0.5 \mathrm{ml}$ of saline, and thereafter returned to their cage to recover. The number of animals used are summarized in Table $\mathbf{1}$.

\section{TISSUE HARVESTING AND SECTIONING}

Mice were sacrificed by an overdose of pentobarbital and transcardially perfused with Tyrode's solution, followed by fixative containing 4\% formaldehyde in phosphate buffer ( $\mathrm{pH}$ 7.0) (APL, Kungens Kurva, Stockholm, Sweden). The brains were removed, post-fixed for $2 \mathrm{~h}$ at $4^{\circ} \mathrm{C}$, rinsed in $0.01 \mathrm{M}$ PBS and transferred to a $0.01 \mathrm{M}$ PBS solution containing $10 \%$ sucrose and stored overnight at $4^{\circ} \mathrm{C}$. Subsequently, brains were frozen and then cut in coronal sections ( $14 \mu \mathrm{m}$ thickness) starting at bregma $-1.5 \mathrm{~mm}$ according to Ref. (22), using a cryostat (Microm International 
Table 1 | Number of animals in the different experimental groups.

\begin{tabular}{clcl}
\hline $\begin{array}{c}\text { Number } \\
\text { of animals }\end{array}$ & Procedure & Survival & Analysis \\
\hline 15 & $\begin{array}{l}\text { pTBI (five per severity } \\
\text { level) }\end{array}$ & $24 \mathrm{~h}$ & Histology \\
& Craniotomy & $24 \mathrm{~h}$ & Histology \\
5 & pTBI (five per severity & $72 \mathrm{~h}$ & Histology \\
15 & level) & & \\
& pTBI (seven per severity & 7 days & Weighing rotarod \\
& level) & & histology \\
7 & Craniotomy & 7 days & Weighing rotarod \\
& & & histology \\
& & &
\end{tabular}

Gmbh, Walldorf, Germany). Sections were thaw-mounted onto gelatine-coated slides and stored at $-20^{\circ} \mathrm{C}$ until staining. For all histological analyses a minimum of five sections separated by $70 \mu \mathrm{m}$ were used.

\section{HEMATOXYLIN AND EOSIN STAINING}

For general brain pathology, sections were stained in hematoxylin (Histolab, Göteborg, Sweden) for $15 \mathrm{~min}$; rinsed in water (15 min); stained with eosin (Sigma-Aldrich, St. Louis, MO, USA) for $2 \mathrm{~min}$; dehydrated through a series of increasing ethanol concentrations; and finally immersed in xylene for $15 \mathrm{~min}$ and cover-slipped with Entellan (Merck, Darmstadt, Germany). For image analysis, pictures were imported into the Image $\mathrm{J}$ software $(\mathrm{NIH}){ }^{2}$ The lesioned area was traced manually after calibration against an internal scale bar and measured using the area-function.

\section{FLUORO-JADE STAINING}

To detect degeneration of cortical neurons, sections were stained with Fluoro-Jade C (Millipore, Billerica, MA, USA) according to the manufacturers' instructions. Briefly, slides were immersed in $80 \% \mathrm{EtOH}$ with $1 \% \mathrm{NaOH}$ for $5 \mathrm{~min}$, followed by $2 \mathrm{~min}$ in $70 \%$ $\mathrm{EtOH}, 2 \mathrm{~min}$ in distilled water, and incubated in $0.06 \%$ potassium permanganate solution for $10 \mathrm{~min}$. Slides were subsequently rinsed in water, transferred to a $0.0001 \%$ solution of Fluoro-Jade C in $0.1 \%$ acetic acid. The slides were then rinsed in distilled water, air dried, and cleared in xylene and cover-slipped with Entellan (Merck).

\section{IMMUNOHISTOCHEMISTRY}

The slides were incubated with primary antibodies overnight at $4^{\circ} \mathrm{C}$. The following antibodies were used: anti-Ibal to label macrophages/microglia (1:400, Wako Pure Chemical Industries, Ltd., Osaka, Japan), anti-GFAP to label astrocytes (1:200, SigmaAldrich), and anti- $\beta$-amyloid precursor protein ( $\beta$ APP) as a marker for early axonal damage (1:200, Invitrogen, Camarillo, CA, USA). After three 10-min rinses in 0.01 M PBS, the sections were incubated for $1 \mathrm{~h}$ at room temperature with Cy-2-secondary antibodies (1:200, Jackson Immunoresearch, PA, USA) and/or

${ }^{2}$ http://rsbweb.nih.gov/ij/
Cy3-secondary antibodies (1:400, Jackson Immunoresearch, PA, USA). For IgG-staining, sections were incubated with anti-rat Cy-2 conjugated antibodies (1:400, Jackson Immunoresearch, PA, USA) overnight, rinsed in PBS, and cover-slipped. Sections were examined using a Nikon E600 microscope (Nikon, Shinjuku, Japan) with appropriate filter settings. Images were captured using a Nikon Digital Sight DS-U1 (5 megapixel) camera, controlled with Nikon EclipseNet software. For image densiometry analysis, pictures were imported into the Image J software, converted to grayscale and eight-bit format, and quantified using the area fraction function. Slides used for quantification were blind-coded prior to analysis.

\section{MOTOR PERFORMANCE}

Using the rotarod test, motor scoring was performed before, and at $1,2,3,4,5,6$, and 7 days after injury. This test is one of the most sensitive tests to detect motor deficits in rodent brain injury (24). Briefly, the animals were placed on a rotarod device (Ugo Basile, Comerio, Varesi, Italy) and permitted to explore the rotarod at constant speed of $5 \mathrm{rpm}$ for $30 \mathrm{~s}$. Then the mice experienced a period during which, the drum was accelerated to $50 \mathrm{rpm}$ over a course of $4 \mathrm{~min}$. Mice were trained for 3 days prior to injury. The rotarod test was performed by measuring the length of time each animal was able to maintain its balance walking on top of the drum. Trials ended when the animal either fell off the rod or clung to the rod as it made one complete rotation. Each mouse was tested threetimes and the average was recorded (25). All behavioral analyses were done blindly with regard to injury/control.

\section{STATISTICAL ANALYSES}

Statistical analyses were carried out using GraphPad Prism 5.0 (GraphPad Software, La Jolla, CA, USA). Data were tested for normality using the Column Statistics function and passed the Kolmogorov-Smirnov test. Multiple group comparisons were performed using one-way ANOVA followed by Bonferroni's test. Repeated measures ANOVA followed by Bonferroni's test was used for weight and rotarod data.

\section{RESULTS}

\section{IMPACT CHARACTERIZATION}

The motion of the probe, from initial position to when the ferrule was engaged, was $3.55 \mathrm{~mm}$. Following impact by pellet, the depth of the penetration in ballistics gel was $3.99 \pm 0.05 \mathrm{~mm}$ with the 35-bar loading-pressure; $4.23 \pm 0.03 \mathrm{~mm}$ for 50-bar; and $4.61 \pm 0.10 \mathrm{~mm}$ for 100-bar (Figure 2A). The maximum speed was $49.0 \pm 2.6 \mathrm{~m} / \mathrm{s}$ (35-bar loadingpressure); $57.8 \pm 2.5 \mathrm{~m} / \mathrm{s}$ (50-bar); and $68.0 \pm 0.3$ for 100 bar loading-pressure (Figure 2A). Maximum cavity volume was $32.6 \pm 5.5 \mathrm{~mm}^{3}$ (35-bar); $70.2 \pm 12.6 \mathrm{~mm}^{3}$ (50-bar); and $110.8 \pm 28.6 \mathrm{~mm}^{3}$ (100-bar) (Figures 2A,B). The weight of the probe was $1.48 \mathrm{~g}$, which would (using the maximum speed for different pressures given in Figure 2A and the formula $e=1 / 2 m v^{2}$ ) translate into kinetic energy of $1.78 \mathrm{~J}$ for 35 -bar, $2.50 \mathrm{~J}$ for 50 -bar, and 3.42 J for 100-bar loading-pressure.

\section{SURVIVAL}

We found that the choice of the anesthetic agent (i.e., isoflurane) profoundly influenced the survival of mice. Initially, we planned 


\begin{tabular}{|cccc|}
\hline Loading pressure & 35 bar & 50 bar & $100 \mathrm{bar}$ \\
\hline $\begin{array}{c}\text { Probe speed } \\
(\mathrm{m} / \mathrm{s})\end{array}$ & $49.0 \pm 2.6$ & $57.8 \pm 2.5$ & $68.0 \pm 0.3$ \\
$\begin{array}{c}\text { Penetration depth } \\
(\mathrm{mm})\end{array}$ & $4.0 \pm 0.1$ & $4.2 \pm 0.1$ & $4.6 \pm 0.1$ \\
$\begin{array}{c}\text { Cavity volume } \\
\left(\mathrm{mm}^{3}\right)\end{array}$ & $32.6 \pm 5.5$ & $70.2 \pm 12.6$ & $110.8 \pm 28.6$ \\
\hline
\end{tabular}

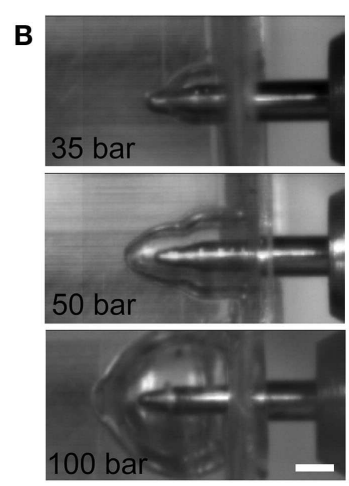

FIGURE 2 | Technical tests of penetration rig. (A) Table showing the relationship between loading-pressure and maximum speed of probe, depth of penetration, and volume of temporary cavity after indentation in ballistic gel (data presented as mean $\pm \mathrm{SD}, n=3-5$ in each condition). (B) Images from high-speed videos used for quantification of temporary cavity (scale bar $=2 \mathrm{~mm}$ )
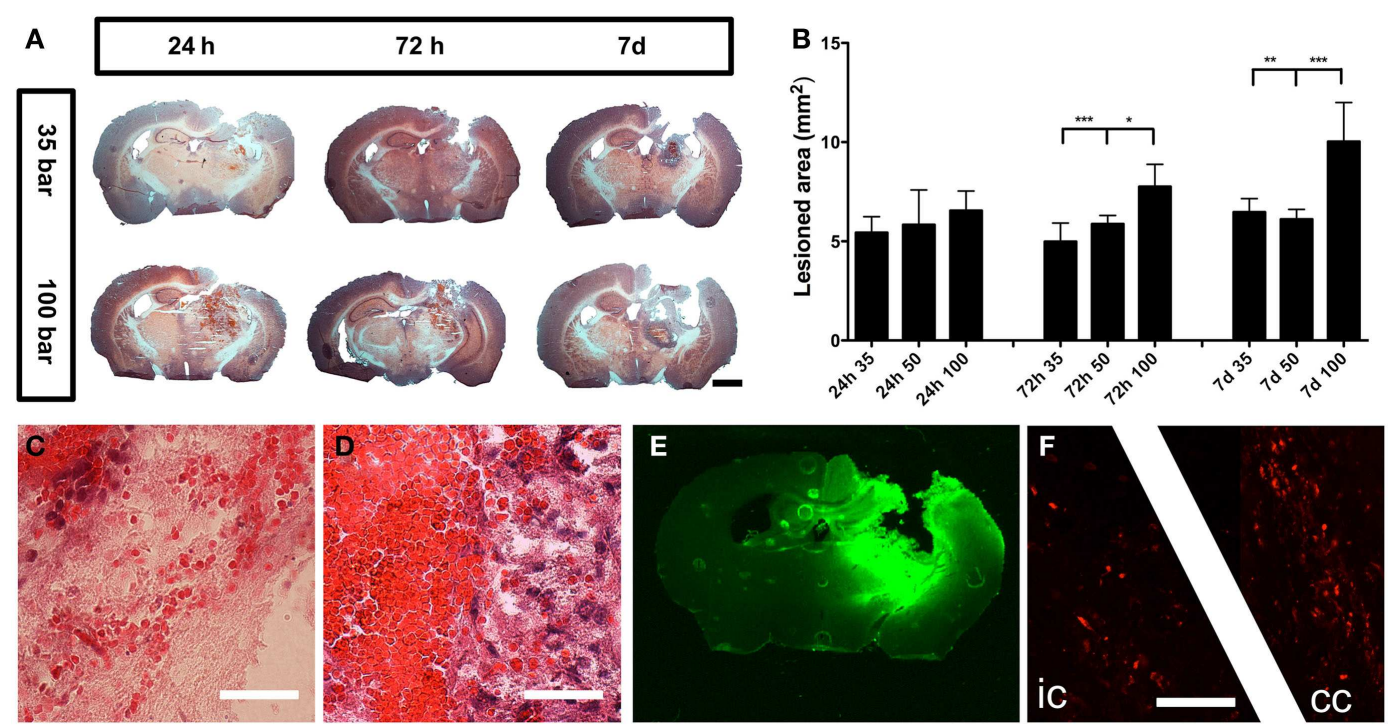

FIGURE 3 | General pathology. (A) Hematoxylin and eosin staining of mice brains subjected to pTBI with 35 and 100-bar loading-pressure, at different time-points post-injury (scale bar $=2 \mathrm{~mm}$ ). (B) Graphs of the injured area at $24,72 \mathrm{~h}$, and 7 days post-injury. Data expressed as mean $\pm \operatorname{SD}$ ( $n=5$ in each group). ${ }^{*} p<0.05,{ }^{* *} p<0.01,{ }^{* *} p<0.001$ (ANOVA followed by Bonferroni's test. (C) Scattered erythrocytes $24 \mathrm{~h}$ post-injury. (D) Massive accumulation of erythrocytes, surrounded by macrophage-rich tissue 7 days after injury (scale bar $=25 \mu \mathrm{m}$ ). (E) IgG-staining showing BBB-defects $24 \mathrm{~h}$ after pTBI. (F) $\beta A P P-p o s i t i v e$ axon profiles in the internal capsule "ic" and corpus callosum "cc" $24 \mathrm{~h}$ after pTBI (scale bar $=50 \mu \mathrm{m}$ ). to use a mixture of fentanyl/fluniasone and midazolam (Hypnorm and Dormicum), as we used in our rat pTBI model (19). However, the small pilot study we conducted to find the optimal experimental setting showed that the survival rate of mice was very low with this regimen of anesthesia, i.e., approximately 50\% in all conditions. Hence, we therefore switched to isoflurane anesthesia shown successful in our previous experiments (25-27) and increased the survival rate to $100 \%$ in all conditions. This observation is in line with the notion by Statler and co-workers (28), who showed that the use of isoflurane was associated with better cognitive recovery and increased neuronal survival compared to several other common anesthetics after controlled cortical impact (CCI) head injury.

\section{HISTOPATHOLOGY OF TISSUE DAMAGE}

The injury caused severe damage to the lateral and medial parietal cortices, corpus callosum, hippocampus, and several parts of the posterior thalamus (Figure 3A). The injury was progressive, and at 7 days post-injury, the initial stage of cavity formation became visible (Figure 3A). The area of injury caused by the 100-bar loading-pressure was significantly larger than the size of damages caused by the 35- or 50-bar loading-pressures, at both $72 \mathrm{~h}$ and 7 days post-injury (Figure 3B). While the erythrocytes in the brain showed a scattered pattern at $24 \mathrm{~h}$ post-injury (Figure $3 \mathrm{C}$ ), at 7 days post-injury, they were found in a confined location, surrounded by dense, macrophage-rich, and tissue (Figure 3D). Positive IgG-staining (Figure 3E) indicating BBB-disruption was 


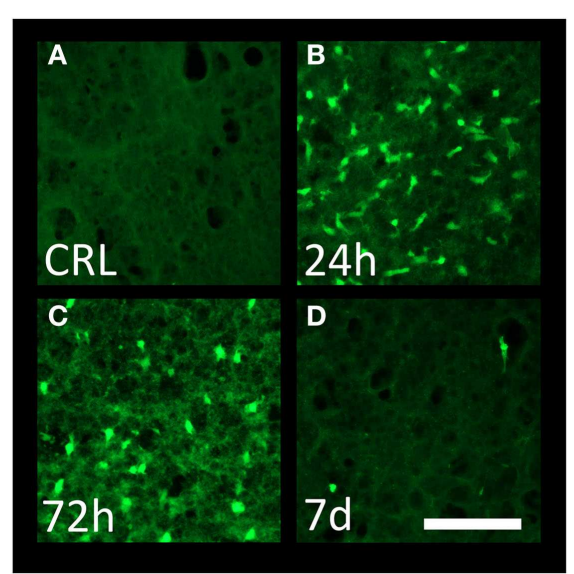

FIGURE 4 | Neuron degeneration. Fluoro-Jade staining in the perilesional area in uninjured (A) and injured (B-D) cortex. All images showing cortex from mice injured at 100-bar severity. Star in insert in (E) indicates the area

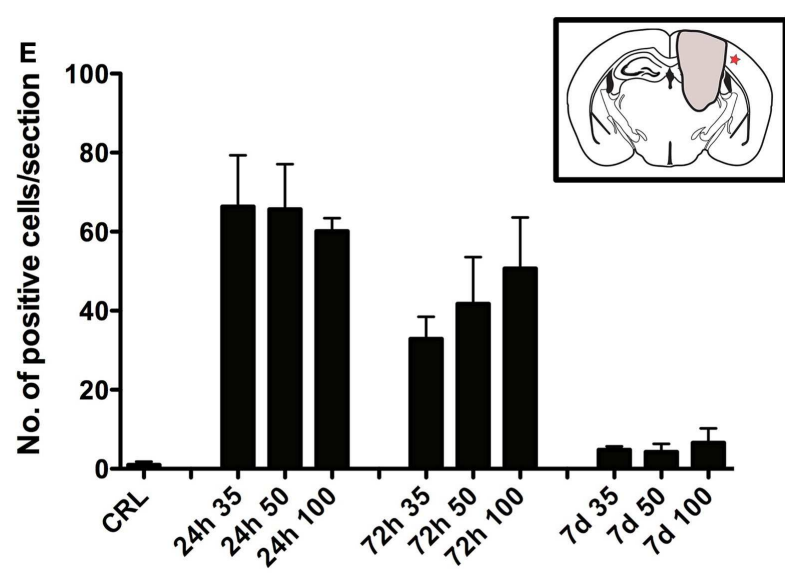

depicted in (A-D) (scale bar $=50 \mu \mathrm{m}$ ). (E) Graph showing the number of Fluoro-Jade-labeled neuronal profiles ( $n=5-6$ in each group, data expressed as mean $\pm \mathrm{SD}$ ). found throughout the lesion and largely confined to the ipsilateral side of the brain. Positive $\beta$ APP-staining indicating axonal damage was observed in white matter tracts (corpus callosum and the internal capsule) at $24 \mathrm{~h}$ post-injury (Figure 3F).

\section{NEURONAL DEGENERATION}

Degeneration of cortical neurons was assessed by Fluoro-Jade staining. While no staining was observed in control animals (Figure 4A), there was a significant increase in the number of labeled neurons at $24 \mathrm{~h}$ post-injury (Figures 4B,E), with diminishing numbers at $72 \mathrm{~h}$ (Figures 4C,E), and 7 days (Figures 4D,E). The trend was similar in all injury severities, and no statistical difference between severity levels could be detected (Figure 4E).

\section{REACTIVE GLIOSIS}

Cortical gliosis was quantified in the peri-lesion area by image densitometry of GFAP (Figures 5A,B) and Iba1-staining (Figures 5D,E) intensity. An increase in GFAP-staining could be detected after $72 \mathrm{~h}$; after that, the staining intensity further increased and remained so to the end of the observation period (7 days post-trauma) (Figure 5C). At 7 days post-injury, gliosis induced by the 100-bar loading-pressure demonstrated a significantly higher GFAP immunoreactivity compared to 35 or 50-bar loading-pressure-induced changes; nevertheless, this was not the case at 24 or 72 days after the injury. The changes of macrophages/microglia showed a similar time-course of activation (Figure 5F), with the exception that the 100-bar loading-pressureinduced injury severity was significantly higher than those caused by the 35 -bar loading-pressure at $72 \mathrm{~h}$ post-injury.

\section{BODYWEIGHT}

At $24 \mathrm{~h}$ after injury, sham control animals had lost $1.0 \pm 3.1 \%$ of their bodyweight, whereas injured animals had lost $7.6 \pm 4.4 \%$ (35-bar), $9.5 \pm 6.4 \%$ (50-bar), and $10.4 \pm 4.5 \%$ (100-bar) (Figure 6). After that, there was a gradual increase in weight in all groups, and at the end of the experiment ( 7 days post-injury), sham control mice had gained $2.9 \pm 3.4 \%$ compared to a loss of
$2.1 \pm 2.3 \%$ for the 35-bar group, $2.4 \pm 2.2 \%$ for the 50-bar group, and $4.3 \pm 3.6 \%$ for the 100 -bar group ( $n=6$ in all groups).

\section{MOTOR FUNCTION}

Animals were tested immediately prior to injury (“T0" in Figure 7), and then daily up to 7 days post-injury. The average "T0" time was $187 \pm 6 \mathrm{~s}$. At $24 \mathrm{~h}$ post-injury, the average time the sham control group $(n=6)$ spent on the rotarod was $163 \pm 16 \mathrm{~s}$ followed by a rapid improvement to the "T0" level. At $24 \mathrm{~h}$ post-injury, the time spent on the rotarod decreased to $110 \pm 23 \mathrm{~s}$ for the 35-bar group, to $107 \pm 33 \mathrm{~s}$ for the 50 -bar group, and $100 \pm 34 \mathrm{~s}$ for the 100 -bar group ( $p<0.01$ for 35 and 50-bar, $p<0.001$ for 100-bar compared to control, $n=7$ in all groups). The 35 and 50-bar groups then gradually regained function, and at day 6 post-injury, they were not statistically different from the control group. However, the 100-bar group still had severe functional deficits by 7 days, $125 \pm 30 \mathrm{~s}(p<0.001)$.

\section{DISCUSSION}

\section{MICE AS MODEL ORGANISM IN EXPERIMENTAL TBI RESEARCH}

Several TBI models, originally developed for other species, have been adapted for use in mice such as the fluid-percussion (29), CCI (30), weight-drop $(25,31,32)$, and the shock tube-generated blast-induced neurotrauma $(27,33)$ models.

However, for mice, the only routinely used model of pTBI is the stab wound, commonly performed using a scalpel or a needle. Although this model is useful for detailed investigations of cellular reactions such as axotomy, astro- and microgliosis, or induction of inflammatory mediators, it bares little resemblance to penetrating TBI seen in the clinic (21). Despite several obvious differences between the brains of humans and rodents in general that should not be overlooked in experimental TBI research (16,34-36), genealtered mice have been used to investigate a number of biochemical pathways and genetic polymorphisms of importance for outcome after TBI $(21,37)$. We are therefore confident that our new model will contribute to a greater understanding of the injury progression of, and outcome after, penetrating TBI. 

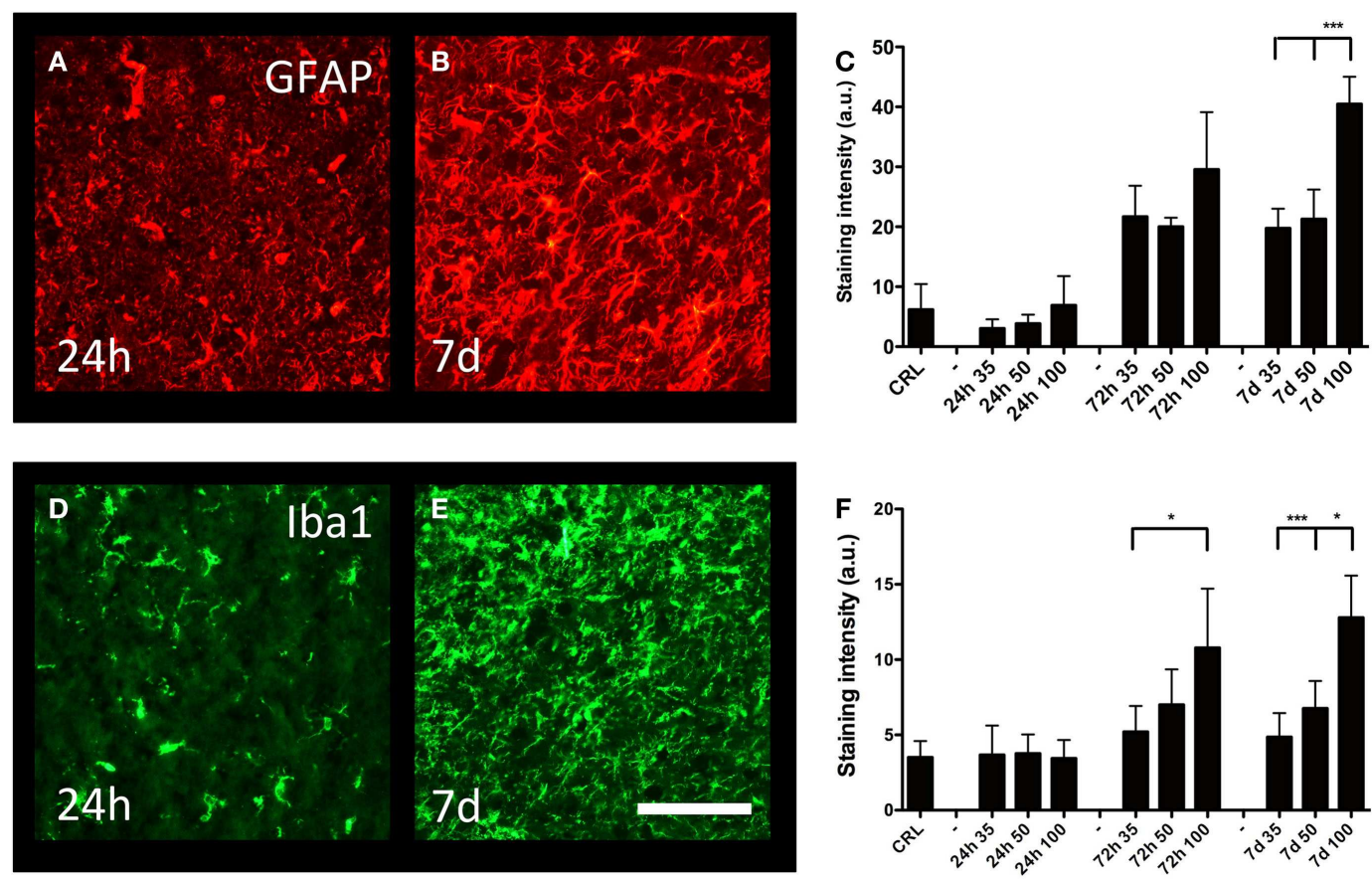

FIGURE 5 | Astro- and microgliosis. GFAP-staining in the perilesional area (same area as in Figure 4E), at $24 \mathrm{~h}$ (A) and 7 days (B) post-injury, both with 100-bar loading-pressure. (C) Graph showing the staining intensity at 24, 72 h, and 7 days post-injury for 35-, 50-, and 100-bar loading-pressure. Data expressed as mean \pm SD $\left(n=5\right.$ in each group, ${ }^{* * *} p<0.001$ ANOVA followed by Bonferroni's test. Iba1-staining (D,E) after 100-bar loading-pressure. (F) Graph of staining intensity at 24, 72 h, and 7 days post-injury for 35-, 50-, and 100-bar loading-pressure. Data expressed as mean \pm SD $(n=5$ in each group). ${ }^{*} p<0.05,{ }^{*} p<0.01,{ }^{* *} p<0.001$ (ANOVA followed by Bonferroni's test). Scale bar $=50 \mu \mathrm{m}$

\section{PERFORMANCE OF THE pTBI DEVICE}

Our technical characterization showed that by using three different loading-pressure levels, we were able to produce three different levels of impact severity as determined by speed, penetration depth, and cavity formation (Figures 2A,B). The volume of an adult C57/Bl6 mouse brain is approximately $453 \mathrm{~mm}^{3}$ (38), which would indicate that the temporary cavity observed in our gel indentation experiments would take up approximately 7\% (35bar), 15\% (50-bar), or 27\% (100-bar) of the mouse brain volume. However, in addition to possible difference in material properties, the temporary cavity observed after pTBI is greatly modified by the irregular shape of the cranial vault and the connective tissue surrounding the brain (39), which makes extrapolations from the gel indentation observations to the in vivo situation rather uncertain. This experiment did, however, confirm that the energy transferred to the surrounding environment (gel or brain tissue) is related to the force used to cause the injury; thus injury is easily scalable (16).

In experiments using cats, Carey and co-workers (12) found that a missile fired at the brain with a kinetic energy of $2.50 \mathrm{~J}$ was fatal in two-thirds of all cases, and with $1.40 \mathrm{~J}$, fatality was around $40 \%$. However, in our model, all injury levels (1.78 J for 35-bar, $2.50 \mathrm{~J}$ for 50-bar, and $3.42 \mathrm{~J}$ for 100 bar) were associated with a complete level of acute phase survival. One of possible explanations is that the kinetic energy in our model was transferred upon impact not only to the brain tissue, but also to the brass ferrule, as evident by the

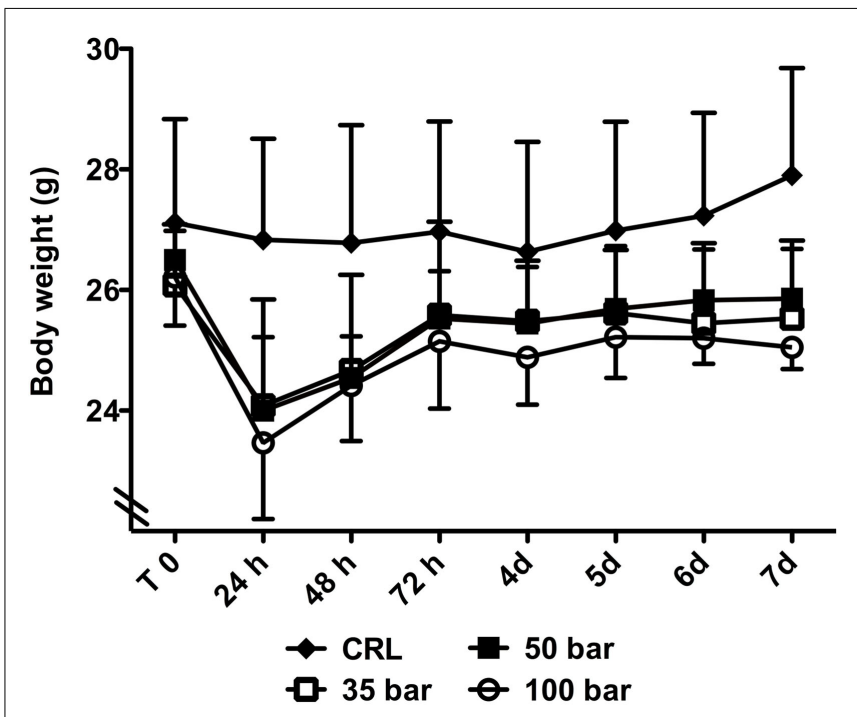

FIGURE 6 | Weight-loss post TBI. Graph showing the bodyweight immediately prior to (TO) and at various time-points post TBI. Data expressed as mean $\pm \mathrm{SD}$ ( $n=7$ in each group). No significant difference between the injured groups could be detected (CRL stands for sham-exposed controls).

deformation of the ferrule (Figure 1D). The exact proportions of energy transferred to ferrule and brain tissue remains to be determined. 


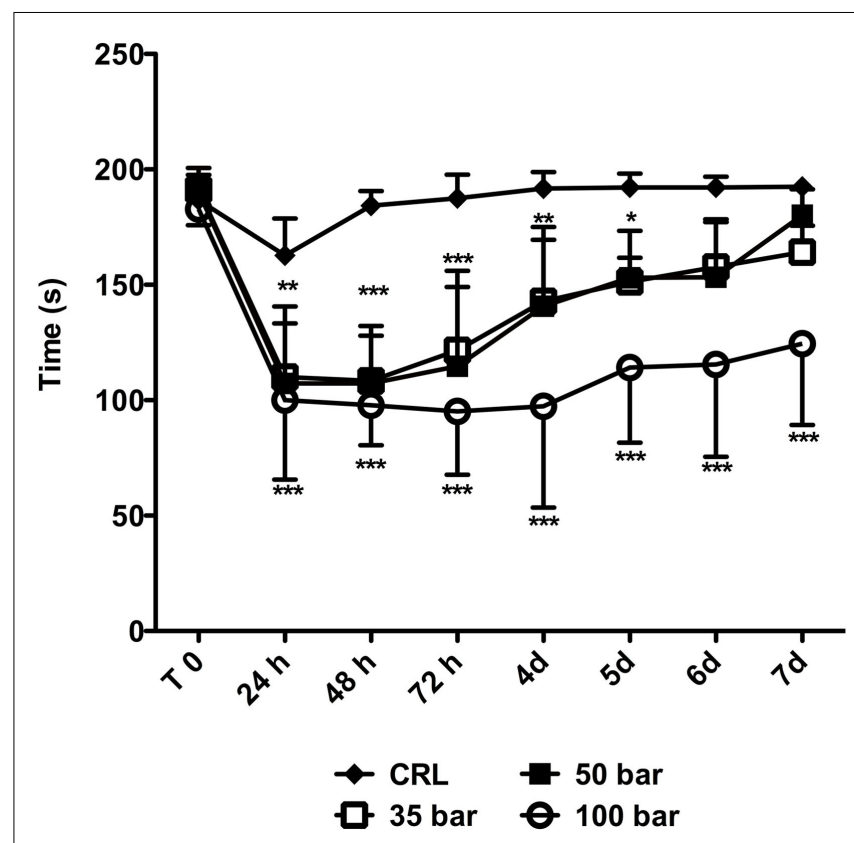

FIGURE 7 | Rotarod-performance post TBI. Graph showing the time on rotarod immediately prior to (T0) and at various time-points post TBI. Data expressed as mean $\pm \mathrm{SD}$ ( $n=7$ in each group). ${ }^{*} p<0.05,{ }^{*} p<0.01$,

${ }^{* * *} p<0.001$ (repeated measures ANOVA followed by Bonferroni's test compared to control)

\section{SURVIVAL}

During these experiments, all animals survived the inflicted pTBI, and only 2 out of 65 animals had to be euthanized according to ethical guidelines due to bad overall condition manifesting as excessive weight-loss and scruffy fur. Our results confirmed the importance of the choice of the anesthetic agent, and the usefulness of isoflurane in neurotrauma research. Similar findings have been reported by Statler et al. describing a neuroprotective effect of isoflurane after CCI (28). The results of our pilot study showed that the anesthesia with fentanyl/fluniasone and midazolam (Hypnorm and Dormicum) mixture we previously used in our rat pTBI study (19) led to $50 \%$ of lethality in all conditions. This further suggests a relative sensitivity of mice to this anesthesia, and caution about its utilization in neurotrauma research.

\section{BODYWEIGHT}

Loss of bodyweight has been reported in mice after CCI (40), fluid-percussion (29), and blast-induced TBI (27) models. In contrast, the PBBI-model did not cause weight-loss in rats (18). In the current experiments, we did observe an initial weight-loss in all pTBI groups, but the mice gradually regained weight, and their bodyweight was not statistically different from controls at the end of the experiment.

\section{MOTOR FUNCTION}

Motor coordination was assessed with the rotarod test, since it has been described as a more sensitive and efficient method than the beam-walking or - balancing tests in detecting motor impairment after brain injury in rodents (24). Spontaneous recovery is commonly seen after experimental TBI $(18,24)$, although the exact biological mechanisms underlying this phenomenon still need further clarification. In the accelerating rotarod test, rats subjected to PBBI (41) and mice injured by lateral CCI (42) showed an initial impairment, followed by gradual recovery to levels comparable to pre-injury after 7 days. This was also the case in the current study for mice subjected to 35- or 50-bar loading-pressure; however, the animals subjected to 100-bar loading-pressure still had a significant impairment at 7 days post-injury. Future studies with longer observation post-injury period are needed to verify whether this motor deficit is permanent. This would be particularly interesting for comparing two mouse TBI models; namely, we have previously observed that mice subjected to mild- or moderate-intensity blastTBI manifested a significantly reduced rotarod-performance from day 1 to 7 days post-injury, but by day 14 , they had recovered to pre-injury levels (27).

\section{NEURONAL INJURY}

We observed a progressive expansion of the injured area over the 7day observation period, when a central cavity was observed. This progressive nature of injury will be examined in future studies, and could form a platform for investigating novel neuroprotective treatments. In the present study, positive Fluoro-Jade staining demonstrating on-going degeneration of neurons in the cerebral cortex was observed at $24 \mathrm{~h}$ post-injury, rapidly declining thereafter. This time-course is in line with previously published results using the PBBI-model (43) or our rat pTBI model (19). Early neurodegeneration could potentially be a signature of the penetrating type of TBI, since Fluoro-Jade staining seems to persist longer, i.e., beyond $24 \mathrm{~h}$ in the CCI model $(44,45)$. Given that many TBI cases contain elements of both focal and diffuse injury types, it has been argued that animal models that fail to generate pathological features of diffuse axonal injury (DAI) are of questionable value (21). In our model, we have observed one DAI hallmark: the accumulation of the $\beta$ APP in white matter tracts (Figure 3F). Although, we have previously reported $\beta$ APP-staining as early as $3 \mathrm{~h}$ post-injury in our rat version of the pTBI model (20), further and more detailed analyses are needed to define the features of DAI in this model.

\section{HEMORRHAGE AND BLOOD-BRAIN-BARRIER DEFECTS}

Hemorrhage and BBB-defects were noted in the lesion area identified by $\operatorname{IgG}$ immunohistochemistry and by the presence of erythrocytes. BBB-defects, edema, and hemmorhage can all increase the intracerebral pressure (ICP). Thus, our findings further emphasize the need for ICP monitoring in experimental models of TBI. Indeed, infrequently used ICP measurement in experimental TBI models has been identified as one of the important discrepancies between clinical and experimental TBIs, which could contribute to difficulties in transferring results from experiments to the clinical arena and vice versa $(35,46,47)$. Hemorrhage can also cause oxidative injury induced by lysed erythrocytes releasing hemoglobin and iron (48-50). The importance of hemorrhage-induced reactive oxygen species in pTBI could be further elucidated in future, using several mouse-strains deficient in pathways involved in protection against oxidative stress (21). 


\section{ASTRO- AND MICROGLIOSIS}

Using our previously described method of semi-quantitative measurements of GFAP and Ibal (19), we analyzed the temporal profile of glial activation in the cortex of mice with pTBI. The statistically significant increase in GFAP immunoreactivity, observed at 72-h and persisting up to 1-week post-injury, was comparable to our findings in the rat pTBI model (19). In contrast, the PBBImodel developed by Williams and co-workers $(18,51)$ generated a somewhat different time-course of astrogliosis. Namely, in their experiments, GFAP was up-regulated already at $6 \mathrm{~h}$ post-injury, peaking at $72 \mathrm{~h}$, whereas only a minor staining level was observed at 7 days post-trauma (51). While the exact reason for this difference is currently unclear, we suggest methodological differences in injury induction (inflated balloon in the Williams model versus propelled projectile in ours) as the most plausible explanation. Reactive astrocytes perform both beneficial and detrimental functions following central nervous system injury (52). The protective functions include removal of excessive amounts of extracellular glutamate (53), resealing the BBB (54), and supporting axonal regeneration $(55,56)$. Astrocytes may also aggravate injury by forming scar tissue that contains inhibitory molecules of axonal regrowth $(57,58)$ and produces proinflammatory cytokines $(59)$. After penetrating injury, astrocytes up-regulate the expression of aquaporin-4 (60), which contributes to edema formation (52). We also analyzed the microglia/macrophage reaction by using Ibal immunohistochemistry. Cortical microglia remained activated up to 7 days post-injury, similar to our previous results in the rat pTBI model (19). However, this activation was longer that the reactive response described in the PBBI-model (51), where at 7 days, only minor levels of microgliosis remained. Similar to astrocytes, activated microglia can perform both protective and harmful tasks such as scavenging, phagocytosis, antigen presentation, synaptic stripping as well as secretion of both pro- and anti-inflammatory mediators $(61,62)$.

\section{CONCLUSION}

In conclusion, we have developed a model for pTBI that reproduces non-fatal penetrating injury in mice. The three levels (i.e., 35-bar, 50-bar, or 100-bar loading-pressures) of the injurious factor (i.e., penetrating probe) were defined in terms of the probe's speed, kinetic energy of the impact, and the size of the damage (i.e., cavitation). These measures were thereafter used to establish a relationship between the intensity of the injurious factor and the severity levels (i.e., mild, moderate, or severe) of the related in vivo injuries measured through several pathological reactions such as tissue destruction, neurodegeneration, gliosis, and motor performance. In most outcome measures, the most severe injury level induced by the 100-bar loading-pressure significantly differed from the mild or moderate injury severities induced by 35-bar or 50-bar loading-pressures, respectively. Nevertheless, no significant differences in the outcome parameters were found between the mild and moderate pTBI groups of mice. For further characterization and standardization, studies with longer observation periods, different injury locations, and/or additional and more sensitive functional tests are required. Finally, it remains to be determined whether the current mouse pTBI model reproduces cognitive impairments such as attention- and reference memory deficits comparable to those we have observed in our previous rat pTBI model (19).

\section{ACKNOWLEDGMENTS}

This work was supported by Karolinska Institutet, the Swedish Brain Foundation, and the Johns Hopkins University Applied Physics Laboratory (Laurel, Maryland, USA) Internal Research and Development (IRAD) funds. The sponsors did not influence the study design, data collection, analysis and interpretation of data, or the report content.

\section{SUPPLEMENTARY MATERIAL}

The Supplementary Material for this article can be found online at http://www.frontiersin.org/Journal/10.3389/fneur.2014.00209/ abstract

\section{Video 1 | Gel impact at 35 bar loading pressure}

Video 2 | Gel impact at $\mathbf{5 0}$ bar loading pressure.

Video 3 | Gel impact at 100 bar loading pressure.

\section{REFERENCES}

1. Damasio H, Grabowski T, Frank R, Galaburda AM, Damasio AR. The return of Phineas Gage: clues about the brain from the skull of a famous patient. Science (1994) 264:1102-5. doi:10.1126/science.8178168

2. Luria A. The Man with a Shattered World: The History of a Brain Wound. Cambridge, MA: Harvard University Press (1987).

3. Squire LR, Amaral DG, Zola-Morgan S, Kritchevsky M, Press G. Description of brain injury in the amnesic patient N.A. based on magnetic resonance imaging. Exp Neurol (1989) 105:23-35. doi:10.1016/0014-4886(89)90168-4

4. Meyer K, Helmick K, Doncevic S, Park R. Severe and penetrating traumatic brain injury in the context of war. J Trauma Nurs (2008) 15:185-9. doi:10.1097/01.JTN.0000343324.55087.de

5. Bell RS, Vo AH, Neal CJ, Tigno J, Roberts R, Mossop C, et al. Military traumatic brain and spinal column injury: a 5-year study of the impact blast and other military grade weaponry on the central nervous system. J Trauma (2009) 66:S104-11. doi:10.1097/TA.0b013e31819d88c8

6. Coronado VG, Xu L, Basavaraju SV, McGuire LC, Wald MM, Faul MD, et al. Surveillance for traumatic brain injury-related deaths - United States, 1997-2007. MMWR Surveill Summ (2011) 60:1-32.

7. Talving P, Benfield R, Hadjizacharia P, Inaba K, Chan LS, Demetriades D. Coagulopathy in severe traumatic brain injury: a prospective study. J Trauma (2009) 66:55-61. doi:10.1097/TA.0b013e318190c3c0

8. Annegers JF, Hauser WA, Coan SP, Rocca WA. A population-based study of seizures after traumatic brain injuries. N Engl J Med (1998) 338:20-4. doi:10.1056/NEJM199801013380104

9. Ishikawa E, Meguro K, Yanaka K, Murakami T, Narushima K, Aoki T, et al. Intracerebellar penetrating injury and abscess due to a wooden foreign body - case report. Neurol Med Chir (Tokyo) (2000) 40:458-62. doi:10.2176/nmc.40.458

10. Solmaz I, Kural C, Temiz C, Secer HI, Duz B, Gonul E, et al. Traumatic brain injury due to gunshot wounds: a single institution's experience with 442 consecutive patients. Turk Neurosurg (2009) 19:216-23.

11. Esposito DP, Walker JB. Contemporary management of penetrating brain injury. Neurosurg Quart (2009) 19:249-54. doi:10.1097/WNQ.0b013e3181bd1d53

12. Carey ME, Sarna GS, Farrell JB, Happel LT. Experimental missile wound to the brain. J Neurosurg (1989) 71:754-64. doi:10.3171/jns.1989.71.5.0754

13. Tan Y, Zhou S, Liu Y, Li Z. A gross and microscopic study of cerebral injuries accompanying maxillofacial high-velocity projectile wounding in dogs. J Oral Maxillofac Surg (1998) 56:345-8. doi:10.1016/S0278-2391(98)90113-6

14. Crockard HA, Brown FD, Johns LM, Mullan S. An experimental cerebral missile injury model in primates. J Neurosurg (1977) 46:776-83. doi:10.3171/jns.1977. 46.6.0776

15. Finnie JW. Pathology of experimental traumatic craniocerebral missile injury. J Comp Pathol (1993) 108:93-101. doi:10.1016/S0021-9975(08)80231-9 
16. Cernak I. Animal models of head trauma. NeuroRx (2005) 2:410-22. doi:10. 1602/neurorx.2.3.410

17. Tolias CM, Bullock MR. Critical appraisal of neuroprotection trials in head injury: what have we learned? NeuroRx (2004) 1:71-9. doi:10.1602/neurorx.1. 1.71

18. Williams AJ, Hartings JA, Lu XC, Rolli ML, Dave JR, Tortella FC. Characterization of a new rat model of penetrating ballistic brain injury. J Neurotrauma (2005) 22:313-31. doi:10.1089/neu.2005.22.313

19. Plantman S, Ng KC, Lu J, Davidsson J, Risling M. Characterization of a novel rat model of penetrating traumatic brain injury. J Neurotrauma (2012) 29:1219-32. doi:10.1089/neu.2011.2182

20. Risling M, Plantman S, Angeria M, Rostami E, Bellander BM, Kirkegaard $\mathrm{M}$, et al. Mechanisms of blast induced brain injuries, experimental studies in rats. Neuroimage (2011) 54(Suppl 1):S89-97. doi:10.1016/j.neuroimage.2010. 05.031

21. Zhang YP, Cai J, Shields LB, Liu N, Xu XM, Shields CB. Traumatic brain injury using mouse models. Transl Stroke Res (2014) 5:454-71. doi:10.1007/s12975014-0327-0

22. Paxinos G, Franklin KBJ. The Mouse Brain in Stereotaxic Coordinates. Amsterdam; Boston: Elsevier Academic Press (2004).

23. Paxinos G, Watson C. The Rat Brain in Stereotaxic Coordinates. Amsterdam; Boston: Elsevier Academic Press (2007).

24. Hamm RJ, Pike BR, O'Dell DM, Lyeth BG, Jenkins LW. The rotarod test: an evaluation of its effectiveness in assessing motor deficits following traumatic brain injury. J Neurotrauma (1994) 11:187-96. doi:10.1089/neu.1994. 11.187

25. Cernak I, Ahmed AF. A comparative analysis of blast-induced neurotrauma and blunt-traumatic brain injury reveals significant differences in injury mechanisms. Med Data (2010) 2:297-304.

26. Cernak I. The importance of systemic response in the pathobiology of blastinduced neurotrauma. Front Neurol (2010) 1:151. doi:10.3389/fneur.2010.00151

27. Cernak I, Merkle AC, Koliatsos VE, Bilik JM, Luong QT, Mahota TM, et al. The pathobiology of blast injuries and blast-induced neurotrauma as identified using a new experimental model of injury in mice. Neurobiol Dis (2011) 41:538-51. doi:10.1016/j.nbd.2010.10.025

28. Statler KD, Alexander H, Vagni V, Dixon CE, Clark RS, Jenkins L, et al. Comparison of seven anesthetic agents on outcome after experimental traumatic brain injury in adult, male rats. J Neurotrauma (2006) 23:97-108. doi:10.1089/neu.2006.23.97

29. Carbonell WS, Maris DO, McCall T, Grady MS. Adaptation of the fluid percussion injury model to the mouse. J Neurotrauma (1998) 15:217-29. doi:10.1089/neu.1998.15.217

30. Smith DH, Soares HD, Pierce JS, Perlman KG, Saatman KE, Meaney DF, et al. A model of parasagittal controlled cortical impact in the mouse: cognitive and histopathologic effects. J Neurotrauma (1995) 12:169-78. doi:10.1089/neu.1995. 12.169

31. Hall ED. High-dose glucocorticoid treatment improves neurological recovery in head-injured mice. J Neurosurg (1985) 62:882-7. doi:10.3171/jns.1985.62.6. 0882

32. Chen Y, Constantini S, Trembovler V, Weinstock M, Shohami E. An experimental model of closed head injury in mice: pathophysiology, histopathology, and cognitive deficits. J Neurotrauma (1996) 13:557-68.

33. Goldstein LE, Fisher AM, Tagge CA, Zhang XL, Velisek L, Sullivan JA, et al. Chronic traumatic encephalopathy in blast-exposed military veterans and a blast neurotrauma mouse model. Sci Transl Med (2012) 4:134ra160. doi:10. 1126/scitranslmed.3003716

34. Gennarelli TA. Animate models of human head injury. J Neurotrauma (1994) 11:357-68. doi:10.1089/neu.1994.11.357

35. Statler KD, Jenkins LW, Dixon CE, Clark RS, Marion DW, Kochanek PM. The simple model versus the super model: translating experimental traumatic brain injury research to the bedside. J Neurotrauma (2001) 18:1195-206. doi:10.1089/089771501317095232

36. Morales DM, Marklund N, Lebold D, Thompson HJ, Pitkanen A, Maxwell WL, et al. Experimental models of traumatic brain injury: do we really need to build a better mousetrap? Neuroscience (2005) 136:971-89. doi:10.1016/j.neuroscience. 2005.08.030

37. Brody DL, Mac Donald C, Kessens CC, Yuede C, Parsadanian M, Spinner $\mathrm{M}$, et al. Electromagnetic controlled cortical impact device for precise, graded experimental traumatic brain injury. J Neurotrauma (2007) 24:657-73. doi:10.1089/neu.2006.0011

38. Ma Y, Hof PR, Grant SC, Blackband SJ, Bennett R, Slatest L, et al. A threedimensional digital atlas database of the adult C57BL/6J mouse brain by magnetic resonance microscopy. Neuroscience (2005) 135:1203-15. doi:10.1016/j. neuroscience.2005.07.014

39. Jandial R, Reichwage B, Levy M, Duenas V, Sturdivan L. Ballistics for the neurosurgeon. Neurosurgery (2008) 62:472-80. doi:10.1227/01.neu.0000316015. $05550.7 \mathrm{a}$

40. Zweckberger K, Stoffel M, Baethmann A, Plesnila N. Effect of decompression craniotomy on increase of contusion volume and functional outcome after controlled cortical impact in mice. J Neurotrauma (2003) 20:1307-14. doi:10.1089/089771503322686102

41. Shear DA, Lu XC, Bombard MC, Pedersen R, Chen Z, Davis A, et al. Longitudinal characterization of motor and cognitive deficits in a model of penetrating ballistic-like brain injury. J Neurotrauma (2010) 27:1911-23. doi:10.1089/neu. 2010.1399

42. Clausen F, Hanell A, Bjork M, Hillered L, Mir AK, Gram H, et al. Neutralization of interleukin-1beta modifies the inflammatory response and improves histological and cognitive outcome following traumatic brain injury in mice. Eur J Neurosci (2009) 30:385-96. doi:10.1111/j.1460-9568.2009.06820.x

43. Williams AJ, Hartings JA, Lu XC, Rolli ML, Tortella FC. Penetrating ballisticlike brain injury in the rat: differential time courses of hemorrhage, cell death, inflammation, and remote degeneration. J Neurotrauma (2006) 23:1828-46. doi:10.1089/neu.2006.23.1828

44. Hall ED, Bryant YD, Cho W, Sullivan PG. Evolution of post-traumatic neurodegeneration after controlled cortical impact traumatic brain injury in mice and rats as assessed by the de Olmos silver and fluorojade staining methods. J Neurotrauma (2008) 25:235-47. doi:10.1089/neu.2007.0383

45. Yang L, Afroz S, Michelson HB, Goodman JH, Valsamis HA, Ling DS. Spontaneous epileptiform activity in rat neocortex after controlled cortical impact injury. J Neurotrauma (2010) 27:1541-8. doi:10.1089/neu.2009. 1244

46. Agoston DV, Risling M, Bellander BM. Bench-to-bedside and bedside back to the bench; coordinating clinical and experimental traumatic brain injury studies. Front Neurol (2012) 3:3. doi:10.3389/fneur.2012.00003

47. Xiong Y, Mahmood A, Chopp M. Animal models of traumatic brain injury. Nat Rev Neurosci (2013) 14:128-42. doi:10.1038/nrn3407

48. Davalos A, Castillo J, Marrugat J, Fernandez-Real JM, Armengou A, Cacabelos $\mathrm{P}$, et al. Body iron stores and early neurologic deterioration in acute cerebral infarction. Neurology (2000) 54:1568-74. doi:10.1212/WNL.54.8.1568

49. Wu J, Hua Y, Keep RF, Schallert T, Hoff JT, Xi G. Oxidative brain injury from extravasated erythrocytes after intracerebral hemorrhage. Brain Res (2002) 953:45-52. doi:10.1016/S0006-8993(02)03268-7

50. Xi G, Keep RF, Hoff JT. Mechanisms of brain injury after intracerebral haemorrhage. Lancet Neurol (2006) 5:53-63. doi:10.1016/S1474-4422(05) 70283-0

51. Williams AJ, Wei HH, Dave JR, Tortella FC. Acute and delayed neuroinflammatory response following experimental penetrating ballistic brain injury in the rat. J Neuroinflammation (2007) 4:17. doi:10.1186/17422094-4-17

52. Sofroniew MV, Vinters HV. Astrocytes: biology and pathology. Acta Neuropathol (2010) 119:7-35. doi:10.1007/s00401-009-0619-8

53. Rothstein JD, Dykes-Hoberg M, Pardo CA, Bristol LA, Jin L, Kuncl RW, et al. Knockout of glutamate transporters reveals a major role for astroglial transport in excitotoxicity and clearance of glutamate. Neuron (1996) 16:675-86. doi:10.1016/S0896-6273(00)80086-0

54. Bush TG, Puvanachandra N, Horner CH, Polito A, Ostenfeld T, Svendsen CN, et al. Leukocyte infiltration, neuronal degeneration, and neurite outgrowth after ablation of scar-forming, reactive astrocytes in adult transgenic mice. Neuron (1999) 23:297-308. doi:10.1016/S0896-6273(00)80781-3

55. Frisen J, Haegerstrand A, Risling M, Fried K, Johansson CB, Hammarberg H, et al. Spinal axons in central nervous system scar tissue are closely related to laminin-immunoreactive astrocytes. Neuroscience (1995) 65:293-304. doi:10. 1016/0306-4522(94)00467-J

56. Tom VJ, Doller CM, Malouf AT, Silver J. Astrocyte-associated fibronectin is critical for axonal regeneration in adult white matter. J Neurosci (2004) 24:9282-90. doi:10.1523/JNEUROSCI.2120-04.2004 
57. Fawcett J. Astrocytes and axon regeneration in the central nervous system. JNeurol (1994) 242:S25-8. doi:10.1007/BF00939237

58. Asher RA, Morgenstern DA, Fidler PS, Adcock KH, Oohira A, Braistead JE, et al. Neurocan is upregulated in injured brain and in cytokine-treated astrocytes. J Neurosci (2000) 20:2427-38.

59. Eddleston M, Mucke L. Molecular profile of reactive astrocytes - implications for their role in neurologic disease. Neuroscience (1993) 54:15-36. doi:10.1016/0306-4522(93)90380-X

60. Neal CJ, Lee EY, Gyorgy A, Ecklund JM, Agoston DV, Ling GS. Effect of penetrating brain injury on aquaporin-4 expression using a rat model. J Neurotrauma (2007) 24:1609-17. doi:10.1089/neu.2007.0301

61. Streit WJ, Walter SA, Pennell NA. Reactive microgliosis. Prog Neurobiol (1999) 57:563-81. doi:10.1016/S0301-0082(98)00069-0

62. Cullheim S, Thams S. The microglial networks of the brain and their role in neuronal network plasticity after lesion. Brain Res Rev (2007) 55:89-96. doi:10.1016/j.brainresrev.2007.03.012
Conflict of Interest Statement: The authors declare that the research was conducted in the absence of any commercial or financial relationships that could be construed as a potential conflict of interest.

Received: 21 August 2014; paper pending published: 06 September 2014; accepted: 30 September 2014; published online: 22 October 2014.

Citation: Cernak I, Wing ID, Davidsson J and Plantman S (2014) A novel mouse model of penetrating brain injury. Front. Neurol. 5:209. doi: 10.3389/fneur.2014.00209

This article was submitted to Neurotrauma, a section of the journal Frontiers in Neurology.

Copyright (c) 2014 Cernak, Wing, Davidsson and Plantman. This is an open-access article distributed under the terms of the Creative Commons Attribution License (CC $B Y)$. The use, distribution or reproduction in other forums is permitted, provided the original author(s) or licensor are credited and that the original publication in this journal is cited, in accordance with accepted academic practice. No use, distribution or reproduction is permitted which does not comply with these terms. 